\title{
CRACK-RESISTANT PROPERTIES OF CONCRETE SUBJECTED TO COMBINED DETERIORATION BY HEATING AND CARBONATION
}

\author{
YOSHINORI KITSUTAKA ${ }^{*}$, HIROSHI YAMAUCHI ${ }^{\dagger}$ AND KOICHI MATSUZAWA ${ }^{\dagger \dagger}$ \\ Tokyo Metropolitan University \\ Tokyo, Japan \\ e-mail: kitsu@tmu.ac.jp \\ 'Tokyo Metropolitan University \\ Tokyo, Japan \\ e-mail: hiroshi.y.227@gmail.com \\ †T Tokyo Metropolitan University \\ Tokyo, Japan \\ e-mail: matsuzawa-kouichi@tmu.ac.jp
}

Key words: Heating, Carbonation, Fracture energy, Tension softening diagram

\begin{abstract}
Concrete structures for nuclear power plant may be subjected to the heating action and carbonation action for a long period. Many studies have already reported that the concrete structure subjected to the heating action can be retained by maintaining the heating conditions of not more than $65^{\circ} \mathrm{C}$ under general control standards for nuclear power plant. The effect of the heating should be considered to discuss the long-term safety and durability of concrete structures in the viewpoint of compressive strength, however the fracture properties of concrete, which were important to discuss the crack resistance for the nuclear power plant, are not yet to be clarified. This paper reports on the investigation into the fracture properties of mortar subjected to the effects of heating and carbonation action. The water-cement ratios (W/Cs) of mortar used in this experiment is set to 0.6, 0.8, 1.0. Mortar specimen size was $40 \mathrm{~mm}$ x $40 \mathrm{~mm}$ x $160 \mathrm{~mm}$. After the 28-day water curing at $20^{\circ} \mathrm{C}$, specimens were set in the heating condition of $20^{\circ} \mathrm{C}$ and $65^{\circ} \mathrm{C}$ and carbonation acceleration conditions of $0 \%$ and $5 \%$. After the heating and carbonation acceleration, three-point bending tests were conducted to measure the load versus crack mouth opening displacement (L-CMOD) curves. The fracture energy was estimated by the tension softening diagram (TSD) calculated by the L-CMOD curve based on the poly-linear inverse analysis. Effects of heating and carbonation on the fracture parameters were discussed.
\end{abstract}

\section{INTRODUCTION}

Reinforced concrete structures used for nuclear power plants are prone to be subjected to heating for a long time. If long-term heating is expected to cause moisture escape, then losses in the elastic modulus as well as strength will cause concern, resulting in increases in the elastic strain energy buildup in the structure, which will promote crack propagation. The temperature of such concrete is required to be not more than $65^{\circ} \mathrm{C}$ to ensure durability [1]. Though a number of studies have been conducted on concrete heating, few of them have dealt with this temperature requirement. 
Another point to consider when investigating the safety and durability of reinforced concrete structures is carbonation of concrete. Carbonation is a phenomenon in which alkaline calcium hydroxide in concrete reacts with carbon dioxide in the atmosphere, forming calcium carbonate, reducing the $\mathrm{pH}$ value of concrete to $8.5-10$. As to the progress of carbonation, the rate formula that is used in most cases is based on a theory that the rate of progress is proportional to the square root of the elapsed time. Among the many studies conducted on the carbonation of concrete, the combined action of high heat of up to $65^{\circ} \mathrm{C}$ and carbonation has yet to be fully elucidated.

Active research has also been underway on the tensile properties of concrete in pace with the increase in its strength and toughness in recent years. While the overall failure of concrete is governed by tensile failure, fracture does not occur at once in tension but gradually propagates by the accumulation of a large number of fine cracks within concrete. This forms a phenomenon referred to as tension softening in which tensile force is retained even after the maximum load is attained. Three point bending testing is employed to evaluate such tensile properties, using notched beams, as specified by RILEM [2] and JCI [3].

With a focus on the strength and durability of concrete subjected to a combined effect of heating and carbonation, the authors investigated its crack resistance by conducting fracture toughness tests on mortar specimens.

\section{STUDY OVERVIEW}

\subsection{Outline of specimens}

Table 1 gives the test factors and levels. Tables 2 and 3 list the materials and mixture proportions, respectively.

Table 1: Test factors and levels

\begin{tabular}{c|c}
\hline Factors & Levels \\
\hline Water-cement ratios $(\%)$ & $60,80,100$ \\
\hline Heating temperature $\left({ }^{\circ} \mathrm{C}\right)$ & 20,65 \\
\hline $\mathrm{CO}_{2}$ concentration $(\%)$ & 0,5 \\
\hline
\end{tabular}

Table 2: Materials

\begin{tabular}{c|l|l}
\hline Materials & Type & Sign \\
\hline Cement & $\begin{array}{l}\text { Ordinary portland } \\
\text { cement }\end{array}$ & $\mathrm{C}$ \\
\hline $\begin{array}{c}\text { Fine } \\
\text { aggregate }\end{array}$ & $\begin{array}{l}\text { Hard sandstone crushed } \\
\text { sand } \\
\text { (Sagamihara production) }\end{array}$ & $\mathrm{S}$ \\
\hline
\end{tabular}

Table 3: Materials

\begin{tabular}{c|c|c|c|c}
\hline $\mathrm{W} / \mathrm{C}$ & $\mathrm{S} / \mathrm{C}$ & \multicolumn{3}{|c}{ Weight $\left(\mathrm{kg} / \mathrm{m}^{3}\right)$} \\
\cline { 3 - 5 }$(\%)$ & $(-)$ & $\mathrm{W}$ & $\mathrm{C}$ & $\mathrm{S}$ \\
\hline 60 & 3.0 & 243 & 500 & 1500 \\
\hline 80 & 4.3 & 243 & 376 & 1616 \\
\hline 100 & 5.0 & 214 & 314 & 1571 \\
\hline
\end{tabular}

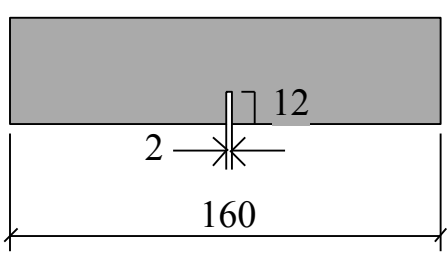

Front

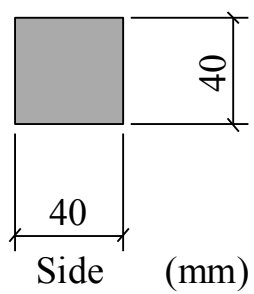

Figure 1: Outline of specimens

Figure 1 shows the outline of specimens, which were fabricated in a thermo-hygrostatic room at $20^{\circ} \mathrm{C}$ and $60 \%$ R.H. Mortar mixed in a mortar mixer with a capacity of 10 liters was placed in steel molds measuring 40 by 40 by $160 \mathrm{~mm}$. Specimens with a water-cement ratio $(\mathrm{W} / \mathrm{C})$ of $60 \%$ and $80 \%$ were demolded 2 days after placing, whereas those with a $\mathrm{W} / \mathrm{C}$ of $100 \%$ were demolded 5 days after placing. These were then water-cured until an age of 4 weeks and then subjected to curing at respective temperature and $\mathrm{CO}_{2}$ concentration conditions at $60 \%$ R.H. Tests were conducted promptly after the time when the specimens for accelerated carbonation tests in $5 \% \mathrm{CO}_{2}$ were carbonated. Note that a notch was cut in each specimen to leave a ligament depth of 28 $\mathrm{mm}$ using a diamond cutter immediately before testing.

\subsection{Outline of tests}

Figures 2, 3, and 4 show the outline of tests, 
test apparatus, and system flow chart of the test setup, respectively. Tests were conducted based on JCI-S-001-2003 (Method of test for fracture energy of concrete using notched beams) [3] using a servo-controlled hydraulic testing machine having a closed loop system manufactured by MTS as shown in Fig. 4. The displacement rate at the notch end was 0.02 $\mathrm{mm} / \mathrm{min}$, which was measured by a sensitive clip gauge to determine a load-crack mouth opening displacement (L-CMOD) curve. Three specimens were used for each set of conditions, and compression tests were conducted using specimens after completion of fracture toughness testing.

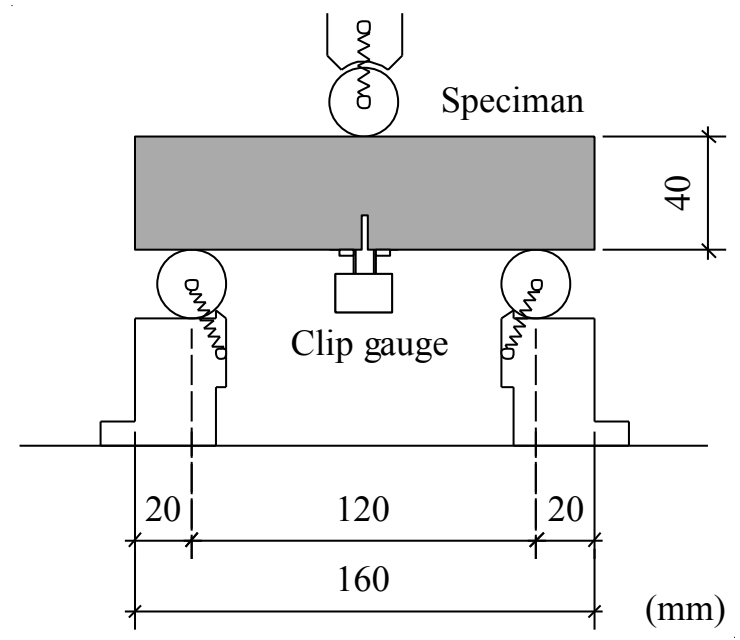

Figure 2: Outline of the fracture toughness test

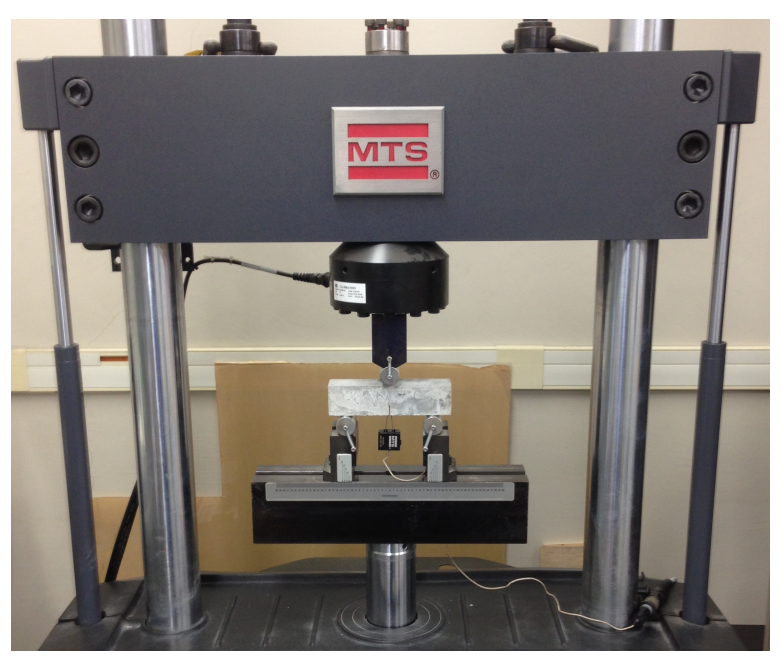

Figure 3: Test apparatus

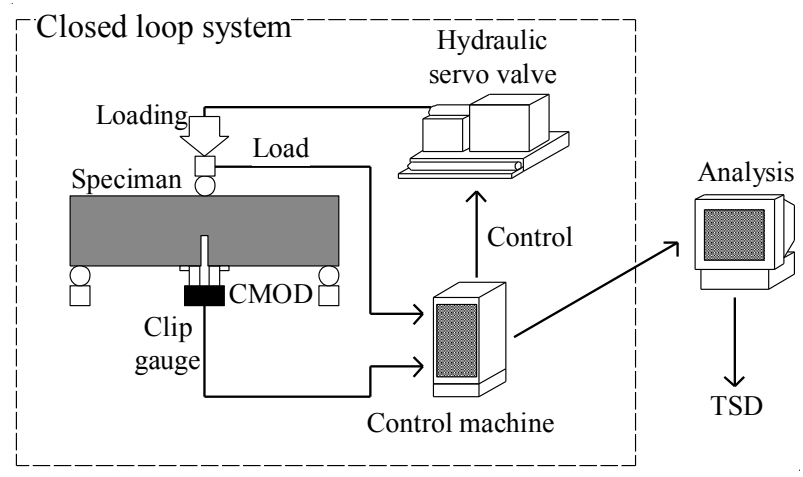

Figure 4: System flow chart of the test setup

Tension softening diagrams (TSDs) were estimated using poly-linear approximation [4] based on the L-CMOD curves obtained from fracture toughness tests. The fracture energy, $G_{\mathrm{F}}$, and initial cohesive stress, $F_{\mathrm{t}}$, were also derived therefrom. A TSD, which is estimated from Poly-linear approximation using LCMOD curve data, represents the relationship between the CMOD and cohesive stress. The initial cohesive stress, which is determined from the initial slope of the L-CMOD curve obtained from fracture toughness testing, represents the cohesive stress when the CMOD is zero on the TSD. This corresponds to the inherent tensile strength of the material. The greater this value, the less prone to crack formation the material is. The fracture energy, which can be determined from the area under the L-CMOD curve, represents the energy accumulated by the time of specimen failure. This corresponds to the area surrounded by the TSD. The greater this value, the less prone to crack propagation the material is.

\section{OUTLINE OF ANALYSIS}

\subsection{Poly-linear approximation of TSD}

This study begins with determination of the L-CMOD curve of each specimen by fracture toughness testing. Based on the results, mode I fracture of concrete is modeled into a fictitious crack model to estimate a TSD using polylinear approximation [4]. A L-CMOD curve is then estimated by analysis from the estimated TSD to minimize the gap with the L-CMOD curve determined from measurement during 
fracture toughness testing. Here the determination of the L-CMOD curve from the TSD is referred to as "analysis," whereas the estimation of a TSD conversely based on the L-CMOD curve is referred to as "back analysis." Though experimentally determinable, the TSD curve can widely vary depending on such factors as the performance and mechanical error of the testing machine. The above-mentioned estimation method is therefore employed to determine the TSD.

\section{TEST RESULTS}

\subsection{Accelerated carbonation}

Table 4 gives the test periods of accelerated carbonation testing until the specimen perfectly carbonated. The carbonation rate coefficient was calculated from the carbonation rate prediction formula based on the test results. Specimens with a higher W/C require a longer period for carbonation. Also, carbonation tends to progress more slowly in specimens cured at $20^{\circ} \mathrm{C}$ than those cured at $65^{\circ} \mathrm{C}$. This is presumably because heating activates $\mathrm{CO}_{2}$ diffusion and carbonation reaction and dries the specimens.

Table 4: Periods of accelerated carbonation testing

\begin{tabular}{|c|c|c|c|c|c|c|}
\hline W/C(\%) & \multicolumn{2}{|c|}{60} & \multicolumn{2}{c|}{80} & \multicolumn{2}{c|}{100} \\
\hline Temperature $\left({ }^{\circ} \mathrm{C}\right)$ & 20 & 65 & 20 & 65 & 20 & 65 \\
\hline Period(weeks) & 48 & 11 & 11 & 6 & 6 & 4 \\
\hline
\end{tabular}

\subsection{Compressive strength}

Figure 5 shows the compressive strength. The strength of specimens cured at $20^{\circ} \mathrm{C}$ is higher than that at 4 weeks, regardless of the $\mathrm{W} / \mathrm{C}$, but that of specimens cured at $65^{\circ} \mathrm{C}$ is lower than that at 4 weeks. Carbonation is found to increase the strength of both $20^{\circ} \mathrm{C}$ and $65^{\circ} \mathrm{C}$-cured specimens. This tendency is more evident with $65^{\circ} \mathrm{C}$-cured specimens, leading to significant increases in strength. Also, the increase in the strength due to carbonation tends to be greater with a lower $\mathrm{W} / \mathrm{C}$. This is presumably due to a lower $\mathrm{S} / \mathrm{C}$, which leads to a higher cement content with a higher void ratio, which leaves greater room for densification by carbonation.

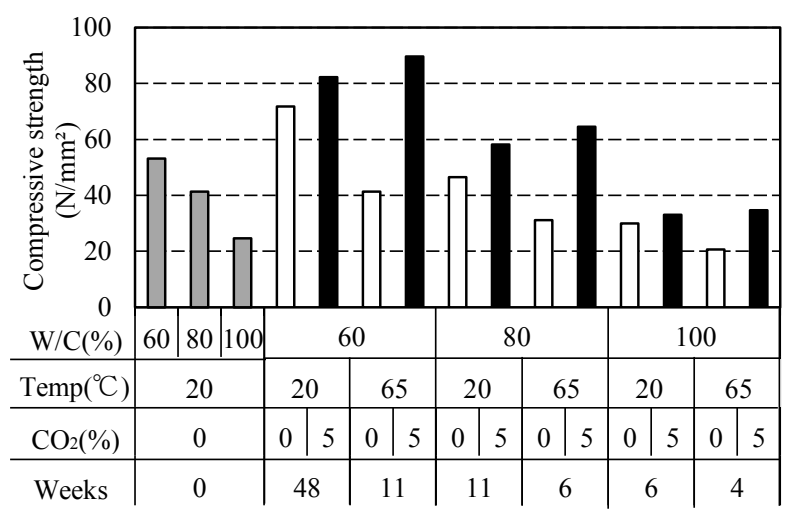

Figure 5: Compressive strength

\subsection{L-CMOD curve}

Figure 6 shows the L-CMOD curves obtained from fracture toughness tests. These curves, which represent the results of three specimens each and their averages, are stable as a whole, but are relatively variable for $20^{\circ} \mathrm{C}$-cured specimens and $65^{\circ} \mathrm{C}$-carbonated specimens. Variabilities are found in not only the maximum load but also the downward slope. There are also unstable curves and curves with a sharp peak due to steep downturn immediately after reaching the maximum load. These variabilities appear to result from the scatter of the degree of hydration in $20^{\circ} \mathrm{C}$-cured specimens and the scatter of the degrees of drying and carbonation-induced densification of the microstructure in $65^{\circ} \mathrm{C}$-cured specimens.

The flexural strength, which is represented by the maximum load, of $20^{\circ} \mathrm{C}$-cured specimens is higher than that earlier at 4 weeks, regardless of the $\mathrm{W} / \mathrm{C}$, presumably due to the progress of hydration in specimens. The strength of carbonated specimens also increases after curing, but is lower than that of uncarbonated specimens with W/Cs of $80 \%$ and $100 \%$. Conversely, however, carbonation causes a substantial increase in the strength of specimens with a $\mathrm{W} / \mathrm{C}$ of $60 \%$, which require 


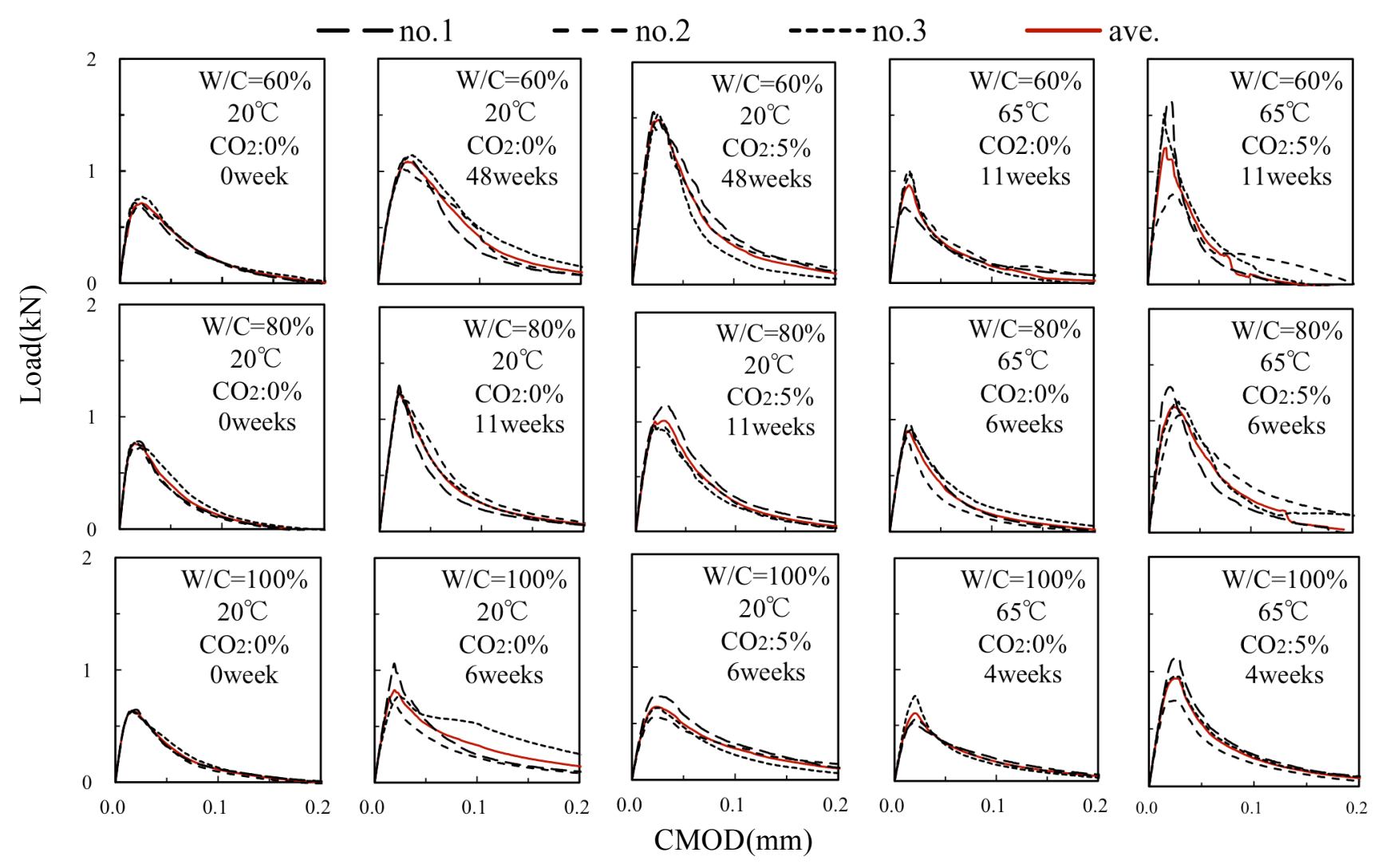

Figure 6: L-CMOD curves

longest time for carbonation. Accordingly, it is presumed that carbonation constrains the strength development at an early stage of an accelerated carbonation test period but in contrast increases the strength at later stages.

One possible reason for this is densification of the microstructure of specimens. As to specimens cured at $65^{\circ} \mathrm{C}$, the strength development tends to be constrained when compared with those cured at $20^{\circ} \mathrm{C}$. This is presumably due to the inhibition of hydration by heating, the coarsening of voids due to moisture escape, the occurrence of microcracks, etc. Nevertheless, the strength of these specimens substantially increases when they are carbonated, with the rate of increase tending to be higher as the $\mathrm{W} / \mathrm{C}$ decreases. One possible reason for this is densification of the microstructure. Also, specimens with significant strength gains demonstrate a sharp drop of the curve immediately after reaching the maximum load, which represents brittle fracture behavior.

\subsection{TSD and initial cohesive stress}

Figures 7 and 9 show the TSDs and initial cohesive stress, respectively.

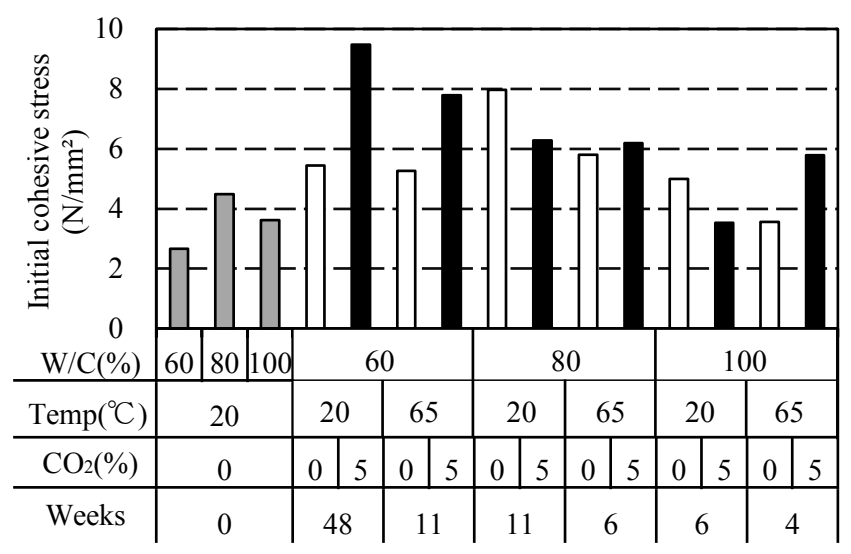

Figure 9: Initial cohesive stress

The initial cohesive stress, $F \mathrm{t}$, tends to increase when carbonated at $20^{\circ} \mathrm{C}$ and decrease when carbonated at $65^{\circ} \mathrm{C}$, similarly to the flexural strength on the L-CMOD curves. 


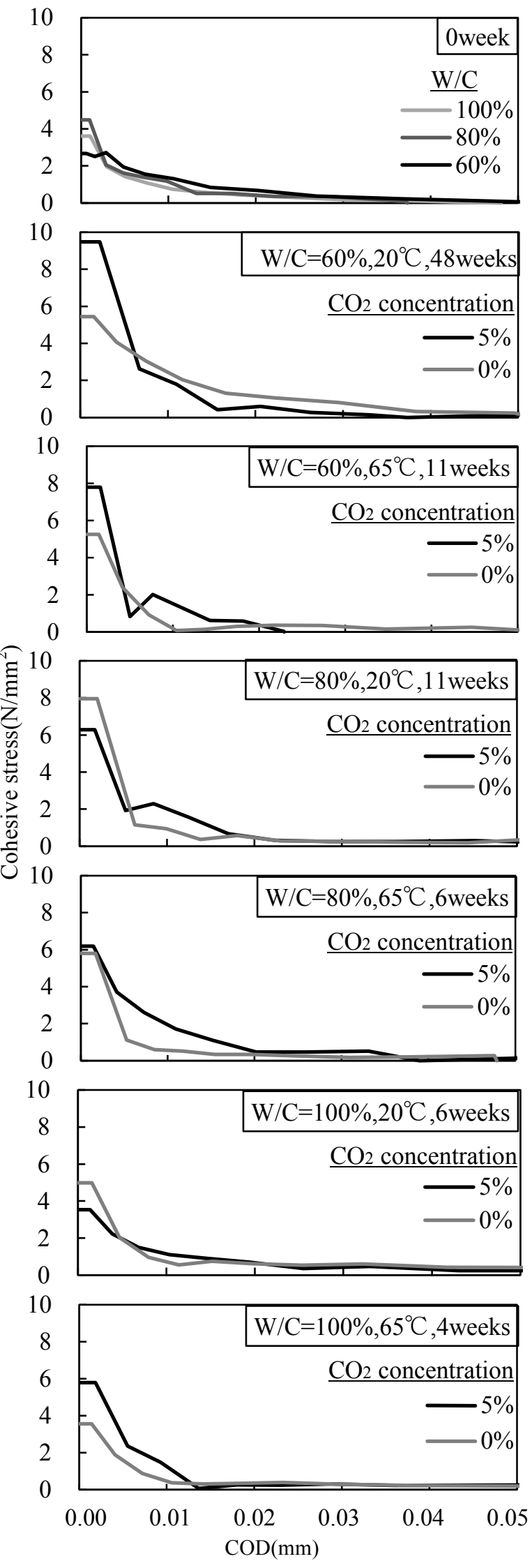

Figure 7: Tension softening diagrams, TSDs
Specimens with a high flexural strength tend to show a high initial cohesive stress. Also, the cohesive stress of specimens with a $\mathrm{W} / \mathrm{C}$ of $60 \%$ and carbonated at $20^{\circ} \mathrm{C}$ tends to be high. Densification by carbonation and the progress of hydration are therefore considered to affect the initial cohesive stress as well. Specimens with a sharp downward slope on the L-CMOD curves also tend to show a sharp drop on the TSDs. These specimens are considered to be brittle, though with a high maximum strength.

\subsection{Fracture energy}

Figure 10 shows the fracture energy, $G_{\mathrm{F}}$. The fracture energy is found also to tend to increase as a whole as carbonation proceeds, similarly to the initial cohesive stress. However, the fracture energy of some specimens is found to be small despite high compressive and flexural strengths. This can be attributed to abrupt softening after the maximum load on the L-CMOD and TSDs. In this manner, the characteristics of the post peak downward gradient of the curves are not simply represented by fracture energy, and strength may not always be correlated with fracture energy.

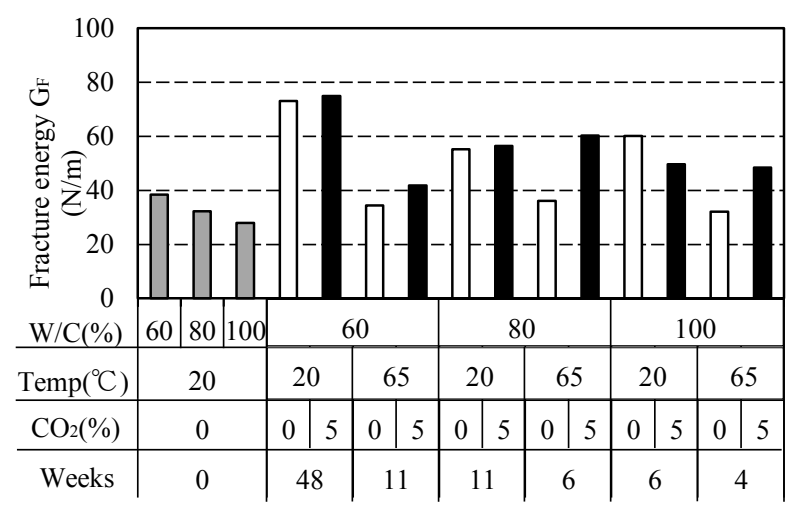

Figure 10 : Fracture energy

\section{CONCLUSIONS}

(1) The strength of specimens cured at $20^{\circ} \mathrm{C}$ is higher than that of specimens at an age of 4 weeks, but the strength development tends to be constrained by carbonation.

(2) The strength of specimens cured at $65^{\circ} \mathrm{C}$ 
is lower than that of specimens at 4 weeks, but significantly becomes higher after carbonation.

(3) The strength of $20^{\circ} \mathrm{C}$-cured specimens may be increased by carbonation at later ages.

(4) The softening rate of specimens with increased strength tends to be high. For this reason, their fracture energy remains low despite their high flexural strength and initial cohesive stress.

\section{ACKNOWLEDGEMENT}

A part of this study was supported by a grant from the Japanese Ministry of Economy, Trade and Industry.

\section{REFERENCES}

[1] Code Requirements for Nuclear Safety Related Concrete Structures (ACI 349-01), Reported by ACI Committee 349.

[2] RILEM Draft Recommendation (1985), "Determination of the Fracture Energy of Mortar and Concrete by Means of Threepoint Bend Test on Notched Beams", Materials and Structures, Vol.18, No.106, pp.285-290.

[3] JCI Standard 2003. Method of test for fracture energy of concrete by use of notched beam. JCI-S-001-2003. Japan Concrete Institute (JCI).

[4] Kitsutaka, Y. 1997. Fracture parameters by polylinear tension-softening analysis. Journal of Engineering Mechanics, ASCE. Vol. 123(5): 444-450. 